\title{
Other Community and Social Services Workers
}

National Cancer Institute

\section{Source}

National Cancer Institute. Other Community and Social Services Workers. NCI Thesaurus.

Code C122538.

Community and social services workers not specifically identified elsewhere. 